\title{
EDITORIAL
}

\section{The only available certification for sexual medicine: The Fellow of the European Committee Sexual Medicine (FECSM)}

(c) The Author(s), under exclusive licence to Springer Nature Limited 2021

IJIR: Your Sexual Medicine Journal (2022) 34:727-729; https://doi. org/10.1038/s41443-021-00506-8

Sexual medicine is one of the most recently evolved branches of medicine. It aims to improve sexual health through prevention, diagnosis, treatment, and rehabilitation of conditions or diseases involving: (i) sexual function and dysfunction; (ii) sexual and/or partnership experience and behavior; (iii) gender identity, orientation, and attractions; (iv) sexual attitudes, feelings, and beliefs; and (v) social expectations and gender [1]. Although its history dates back to ancient ages [2], sexual medicine studies gained momentum after the launch of the first oral erectile dysfunction medication Viagra (Pfizer, New York, USA) in 1999 [3]. After this revolutionary development, the interest on sexual medicine continuously increased among the general population, scientists, medical community, and, more recently, academics. In the recent years there are thousands of physicians dealing with sexual medicine all around the world [4].

However, the evolution of sexual medicine has several obstacles. Although sexual health is one of the most important aspects of quality of life [5], physicians and health organizations underestimate the priority of sexual medicine [6]. One of the reasons for this misunderstanding is the lack of proper sexual medicine education in medical schools and not being recognized globally as a medical specialty $[7,8]$. Sexual medicine is a multidisciplinary field and although our understanding of sexual dysfunctions has vastly improved, sexual medicine and sexology remain fragmented, with practicing doctors and psychologists from tremendously different backgrounds and expertise. On the other hand, patients would greatly benefit from a sexual medicine physician who is knowledgeable and skilled in all areas of sexual care. However, whether the full scope of sexual medicine can be safely practiced by a single physician or therapist is debatable, we will need to train a variety of sexual medicine physicians and sexologists, each with different practical skills but a shared understanding of the field and, perhaps most importantly, the ability to collaborate with one another. Regulation and assessment of education and training, regardless of specialty, is important strategy to promote good standards of medical care. Furthermore, scientific advancement and competency in daily clinical practice can only be achieved through collaboration among scientists [9].

In order to overcome this limitation, on initiative of the European Society for Sexual Medicine (ESSM), a Multidisciplinary Joint Committee for Sexual Medicine (MJCSM) was established (https://www.mjcsm.org), under the umbrella of the Union of European Medical Specialists (UEMS, the regulatory body that oversees specialist medical practice at a European level) (https:// www.uems.eu) [9]. This group includes representatives of the five UEMS boards of dermatology and venerology, endocrinology, obstetrics and gynecology, psychiatry, and urology, which joined the MJCSM with two elected representatives each. The structure of MJCSM and its aims are summarized in Fig. 1.

Since 2012, the MJCSM has set biannual exams to award the qualification of "Fellow of the European Board of Sexual Medicine" (FECSM) to medical doctors from several specialties such as urology, psychiatry, gynecology, internal medicine, and general practice. These exams are prepared by a committee consisted of highly experienced academicians working in the field of sexual medicine. The MJCSM exam has been endorsed for quality assurance by The Council for European Specialists Medical Assessment committee that adapt the Glasgow declaration setting the basic rules governing European Examinations. To date, the MJCSM exam is the only certification for qualification in Sexual Medicine and more than 500 physicians from all over the world gained the FECSM title after fulfilling the eligibility criteria and successfully passing this exam.

Since the main objective of the MJCSM is "to guarantee the highest standards of care in the field of Sexual Medicine," it has many other important tasks. The MJCSM has developed the first endorsed postgraduate curriculum for Sexual Medicine that have been approved by the UEMS as European Standards in Medical Training for sexual medicine (https://www.uems.eu/areas-ofexpertise/postgraduate-training/european-standards-in-medicaltraining) and constantly updating it in accordance with the new findings in the field. Moreover, the MJCSM sets criteria to become a "training centers of Sexual Medicine" and certifies such training centers across Europe. The MJCSM also deals with awareness and educational issues. In 2019, the committee initiated a campaign in the European Parliament to raise awareness of sexual medicine and include sexual health in the undergraduate education [1]. This initiative has been endorsed by the UEMS as a whole and by all the five European specialist boards that are part of the MJCSM. In addition, the committee collaborates with other sexual medicine and sexology organizations on future developments in many projects, such as the European Sexual Medicine Network (ESMN) project that is founded by the European Cooperation in Science and Technology (COST, CA18124) action (www.https://www.esmncost.eu/). The ESMN is an international network of medical science researchers and practitioners, educators, and social service professionals involved with sexual health and medicine [10]. Currently, a Memorandum of Understanding has been signed between the MJCSM and the ESMN to implement the action of its working group devoted on the development of a basic curriculum for university education on sexual medicine. Finally, the collaboration with the ESSM, the scientific society growing under the umbrella of the International Society for Sexual Medicine (www. issm.info), which proposed and founded the MJCSM, warrants continue efforts to develop educational opportunities for professionals of all levels and disciplines of healthcare in the field of sexual health.

Thanks to those collaborations and in a continuous effort to improve the quality of sexual medicine services and education 


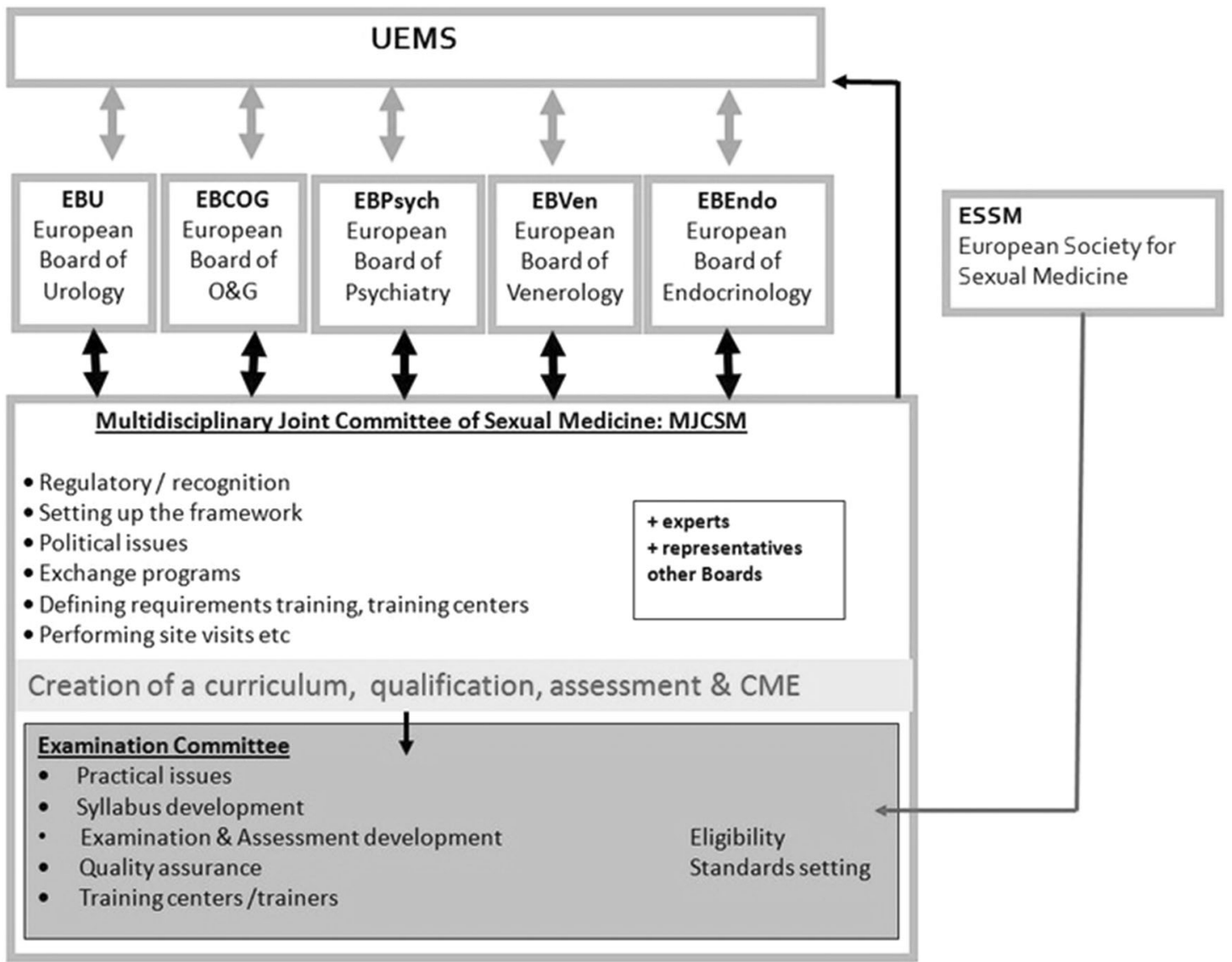

Fig. 1 The structure and aims of Multidisciplinary Joint Committee for Sexual Medicine (MJCSM). Describing the involved European Boards involved.

across Europe and patients' sexual quality of life, the MJCSM will continue to work vigorously.

Ege Can Serefoglu $\mathbb{D}^{1 凶}$, Yacov Reisman ${ }^{2}$, Johannes Bitzer ${ }^{3}$, Linda Vignozzi (D) $^{4}$ and Emmanuele A. Jannini (iD ${ }^{5}$ ${ }^{1}$ Department of Urology, Biruni University, School of Medicine, Istanbul, Turkey. ${ }^{2}$ Flare Health, Amstelveen, The Netherlands. ${ }^{3}$ Klinik

für Geburtshilfe und Gynäkologie, Universitätskrankenhaus Basel,

Basel, Switzerland. ${ }^{4}$ Department of Experimental and Clinical Biomedical Sciences "Mario Serio", University of Florence, Florence,

Italy. ${ }^{5}$ Chair of Endocrinology \& Medical Sexology (ENDOSEX), Department of Systems Medicine, University of Rome Tor Vergata, Rome, Italy. ${ }^{\bowtie}$ email: egecanserefoglu@hotmail.com

\section{REFERENCES}

1. Jannini EA, Reisman Y. Medicine without sexual medicine is not medicine: an MJCSM and ESSM petition on sexual health to the political and university authorities. J Sex Med. 2019;16:943-5. https://doi.org/10.1016/j.jsxm.2019.04.001

2. Verit A, Verit FF. The phallus of the greatest archeological finding of the new millenia: an untold story of Gobeklitepe dated back 12 milleniums. Int J Impot Res. 2021;33:504-7. https://doi.org/10.1038/s41443-020-0300-2

3. Goldstein I, Lue TF, Padma-Nathan H, Rosen RC, Steers WD, Wicker PA. Oral sildenafil in the treatment of erectile dysfunction. Sildenafil Study Group. N Engl J Med. 1998;338:1397-404. https://doi.org/10.1056/NEJM199805143382001. Erratum in: N Engl J Med 1998:339:59. PMID: 9580646

4. Lewis RWG. History of the International Society of Sexual Medicine (ISSM)-the beginnings. J Sex Med. 2008:5:740-5.

5. Flynn KE, Lin L, Bruner DW, Cyranowski JM, Hahn EA, Jeffery DD, et al. Sexual satisfaction and the importance of sexual health to quality of life throughout the life course of U.S. adults. J Sex Med. 2016;13:1642-50. https://doi.org/10.1016/j. jsxm.2016.08.011

6. Cellek S, Giraldi A. Challenges in sexual medicine. Nat Rev Urol. 2012;9:537-42. https://doi.org/10.1038/nrurol.2012.134

7. Eardley I, Reisman Y, Goldstein S, Kramer A, Dean J, Coleman E. Existing and future educational needs in graduate and postgraduate education. J Sex Med. 2017; 14:475-85.

8. Reisman Y, Sarikaya S. Ensuring a bright present and future for sexual medicine. Nat Rev Urol. 2018;15:523-4. https://doi.org/10.1038/s41585-018-0041-x.

9. Reisman Y, Eardley I, Porst H, MJCSM. New developments in education and training in sexual medicine. J Sex Med. 2013;10:918-23.

10. Greil-Soyka M, Quayle E, Bitzer J. European Sexual Medicine Network: a unique platform for collaboration. Int J Impot Res. 2021;33:499-503.

\section{ACKNOWLEDGEMENTS}

The authors would like to express their appreciation for the members of the MJCSM board and the MJCSM exam committee for their tremendous efforts and dedicated contributions for the achievements of the MJCSM. The MJCSM members: E. A. Jannini (IT) - President, E. C. Serefoglu (TR)-Secretary, J. Bitzer (CH)-Treasuerer, J. Dean (UK), F. Fusco (IT), K. Gersak (SI), G. Pagkalos (GR), M. Potocnik (SI), Y. Reisman (NL), and B. Zilaitiene (LTU). The MJCSM exam committee: L. Vignozzi (IT)—Chair, S. Andrews (UK), J. Bitzer (CH), B. Cuzin (F), M. Dewitte (BE), G. Pagkalos (GR), Y. Reisman (NL), and A. Shechter (IL).

\section{AUTHOR CONTRIBUTIONS}

Concept: ECS, YR. Data search: EAJ, LV. Manuscript writing: JB, YR. Editing: ECS, EAJ. Supervisors: YR, JB. 
COMPETING INTERESTS

The authors declare no competing interests.

\section{ADDITIONAL INFORMATION}

Correspondence and requests for materials should be addressed to Ege Can Serefoglu.
Reprints and permission information is available at http://www.nature.com/ reprints

Publisher's note Springer Nature remains neutral with regard to jurisdictional claims in published maps and institutional affiliations. 